\title{
Eye movement control in reading and visual search: Effects of word frequency
}

\author{
KEITH RAYNER \\ University of Massachusetts, Amherst, Massachusetts \\ and \\ GARY E. RANEY \\ University of Illinois, Chicago, Illinois
}

\begin{abstract}
Eye movements were recorded as subjects either read text or searched through texts for a target word. In the reading task, there was a robust word frequency effect wherein readers looked longer at low-frequency words than at high-frequency words. However, there was no frequency effect in the search task. The results suggest that decisions to move the eyes during reading are made on a different basis than they are during visual search. Implications for current models of eye movement control in reading are discussed.
\end{abstract}

The control of eye movements during the reading process has been the topic of a considerable amount of recent research (see, e.g., Rayner, Sereno, \& Raney, in press; Vitu, O'Regan, Inhoff, \& Topolski, 1995). Much of the discussion has focused on the extent to which (1) momentto-moment cognitive processes influence the decision to move the eyes during reading, as in models proposed by Morrison (1984), Henderson and Ferreira (1990), Just and Carpenter (1980), and Pollatsek and Rayner (1990), or (2) low-level oculomotor factors are the primary influence on eye movements, as in models proposed by O'Regan $(1990,1992)$ and Kowler and Anton (1987). Although oculomotor factors undoubtedly have some influence, we believe that the bulk of the evidence is consistent with the view that moment-to-moment cognitive processes play the major role in the decision of when to move the eyes (see Rayner \& Fischer, in press; Rayner et al., in press).

In this article, our concern was not with discriminating between models of eye movement control during reading per se. Rather, we were interested in the possibility that the trigger for initiating an eye movement varies as a function of the task. Specifically, Rayner (1995; Rayner \& Pollatsek, 1992) suggested that the basic mechanisms involved in eye movement control in reading, scene perception, and visual search are similar, but that the decision about when to move the eyes is influenced by different processes (see below). Since Morrison's (1984) model serves for us as the foundation for considering the

This research was supported by Grant HD26765 from the National Institutes of Health. K.R. was also supported by a Research Scientist Award from the National Institute of Mental Health (MH01255). We thank John Henderson, Betty Ann Levy, Randi Martin, and an anonymous reviewer for their helpful comments on an earlier version of the paper. Correspondence should be addressed to K. Rayner, Department of Psychology, University of Massachusetts, Amherst, MA 01003 (email: rayner@psych.umass.edu). basic mechanisms involved in eye movement control, we briefly review his model.

According to Morrison (1984), each eye fixation begins with visual attention focused on the currently fixated word. After processing of the fixated word has reached a criterion level, attention shifts to the word to the right of fixation (word $n+1$ ). The shift of attention initiates processing of the word at the newly attended location and signals the eye movement system to prepare a program to move the eyes to that location. The motor program is executed once it is completed, and the eyes then follow attention to word $n+1$. Because there is a lag between the shift of attention and the movement of the eyes due to programming latency, information is acquired from word $n+1$ before it is fixated. Attention will sometimes then shift to word $n+2$ if word $n+1$ is easy to identify. In these cases, the eye movement program will be changed to send the eyes to word $n+2$ and word $n+1$ will be skipped. Usually there is some cost for doing this and the duration of the fixation prior to a skip is inflated (Hogaboam, 1983; Pollatsek, Rayner, \& Balota, 1986). The cost occurs because the reader had to cancel the motor program for the saccade that was programmed to go to word $n+1$. If the reader is too far into the motor program to cancel the saccade, there will either be (1) a short fixation on word $n+1$ followed by a saccade to word $n+2$ or (2) a saccade that lands at an intermediate position between the two words. The model can thus explain a number of facts about eye movement behavior in reading, including two that had puzzled reading researchers for some time: (1) why there are short fixations (under $150 \mathrm{msec}$ ) in text, given that saccade latencies in simple oculomotor tasks are typically on the order of 175-200 $\mathrm{msec}$, and (2) why the eyes sometimes land in the spaces between words.

In the original model, Morrison (1984) suggested that encoding of the fixated word was the trigger for the at- 
tention shift and subsequent eye movement. Subsequent variations of the model (Henderson \& Ferreira, 1990; Pollatsek \& Rayner, 1990) have equated encoding of the fixated word with lexical access to that word. In these models, lexical access refers to the process of identifying a word's orthographic and/or phonological pattern so that semantic information can be retrieved. Since lexical access is assumed to be influenced by word frequency, fixation time on low-frequency words will be longer than on high-frequency words, as has been demonstrated by a great deal of research (Inhoff \& Rayner, 1986; Just \& Carpenter, 1980; Raney \& Rayner, 1995; Rayner, 1977; Rayner \& Duffy, 1986; Rayner et al., in press; Sereno, 1992).

An important point regarding moment-to-moment cognitive control models of eye movements in reading is that whereas low-level information (like word length and spacing between words) influences the decision about where to move the eyes, the decision of when to move the eyes is determined by moment-to-moment processes. Now consider the case in which subjects are engaged in a visual search task in which they search through text for a specified target word. As noted above, Rayner (1995) has hypothesized that when subjects are asked to search for a target word in text, the same basic processes that Morrison (1984) described come into play except that the trigger for when to move the eyes is different; it may be something like the following: "Is the fixated word the same (in terms of visual or orthographic features) as the target word?" If the answer is "no," the eyes move on. This hypothesis makes a very clear prediction with respect to the effect of word frequency in the task. Specifically, there should not be a frequency effect when the task is visual search because the fixated words need not be processed deeply enough for lexical access to serve as the trigger for the eye movement. On the other hand, as noted, frequency effects are quite robust when the task is reading for meaning: Readers look longer at low-frequency words than at high-frequency words (Inhoff \& Rayner, 1986; Rayner \& Duffy, 1986).

In the present experiment, we asked subjects to either read passages of text or search through the texts for the presence of a target word. Embedded within each passage was either a high- or a low-frequency word (in the same location in the text). The two words were synonyms or near synonyms, with either word fitting in the context of the passage. We anticipated a frequency effect with the reading task but not with the visual search task.

\section{Method}

Subjects. Thirty-two undergraduate students at the University of Massachusetts participated in the study. They either received course credit or were paid $\$ 5.00$ for participating. They all had normal, uncorrected vision and were naive concerning the purposes of the study Sixteen of the subjects participated in the reading version of the study and 16 participated in the visual search version of the study.

Materials. The stimuli consisted of 16 passages used previously by Raney and Rayner (1995). The passages were short narratives consisting of approximately 150 words. The passages appeared on 15 lines of a video monitor with normal punctuation. Embedded within each passage was a target word that was either a high-frequency (HF) or a low- frequency (LF) word. These target words were either synonyms or similar near-synonyms (e.g., flowers-blossoms, ancient-archaic, sharp stark), so that one member of the pair could replace the other in the passage with little change in the meaning being conveyed. HF words had frequencies greater than 60 (mean $=135$ ) and LF words had frequencies of 15 or less (mean $=7$ ) according to the Francis and Kučera (1982) norms. Target word pairs were matched for length whenever possible (mean length for $\mathrm{HF}=7.3$ letters and for $\mathrm{LF}=7.4$ letters).

In both the reading and visual search conditions, half of the passages contained an HF target word and half contained an LF target word for any given subject. Each subject saw an equal number of $\mathrm{HF}$ and LF targets, and counterbalancing procedures ensured that each word appeared equally often in each passage. The target words always occurred in the middle of a line, but the line on which they occurred differed.

Apparatus. Eye movements were monitored from the right eye using a Fourward Technologies Dual Purkinje eyetracker, which has a resolution of $10^{\prime \prime}$ of arc. The eyetracking system was interfaced with an Epson Equity III computer that controlled all aspects of the experiment and sampled the eye position every millisecond. The initiation of a fixation was defined as the point when five consecutive samples each differed from the sample taken $5 \mathrm{msec}$ earlier by less than $1 / 3$ of a character space. The initiation of a saccade was defined as the point when three consecutive samples each differed from the previous sample by more than one third of a character space.

The passages were presented on a Sony monitor with yellow characters on a black background. Characters were made up from a $5 \times 8$ dot matrix and were presented in standard upper- and lowercase format. Characters were separated by three dots horizontally and six dots vertically. Three horizontal characters equaled $1^{\circ}$ of visual angle and the vertical spacing between lines equaled $1.5^{\circ}$ of visual angle ( 1.5 line spacing). All texts occupied 15 lines on the monitor, and the maximum line width was 60 characters. Subjects' eyes were $80 \mathrm{~cm}$ from the monitor, and monitor brightness was adjusted to a comfortable level for each subject.

Procedure. Each subject was tested individually. When subjects arrived at the laboratory, a bite bar was prepared that served to stabilize the head. Subjects were then given instructions about the experiment and a description of the apparatus. They were told that the purpose of the experiment was to determine where people look in passages of text when they are asked to read or search. Subjects in the reading group were told to read the passages in a normal manner and at whatever reading rate they felt comfortable. To encourage them to read for comprehension, they were further instructed that they would be presented with a short "yes-no" question after each passage. They answered these questions correctly $92 \%$ of the time.

Subjects in the search group were told to search the passage for a target word (the search target) and to push a response key if they found the word in the passage. Prior to each passage, the experimenter read the search target word to the subjects. Half the passages contained a search target and half did not. For the half of the trials when there was a search target, it occurred at least two lines after the HF or LF target word. The search target was always of approximately the same length as the HF and LF target words. Subjects in the search group were told to scan the passages from left to right to mimic reading, but that there was no necessity of processing the meaning of the individual words. They were further encouraged to search as fast as they could. Subjects were very accurate in their search: They missed the target word less than $2 \%$ of the time and made a false alarm less than $1 \%$ of the time.

After subjects received their appropriate instructions, the eyetracker was calibrated for each subject. Prior to each passage, five fixation boxes were displayed where the first line of text would be shown. The subject was instructed to look at the right-most box, the center box, and then the left-most box (which indicated the position of the first letter in the text). If the calibration was satisfactory, the experimenter presented the passage; if it was not, the subject was recalibrated. After reading or searching the passage, the subject pressed a response key, which cleared the monitor screen. In the reading condition, the subject then answered a short comprehension question; in the search condition, the subject indicated whether the search target was present or not. Then the cycle began again with the calibration check. 


\section{Results}

Fixation time on the HF and LF target words was examined as a function of the assigned task (reading or visual search). Across all the trials, just under $4 \%$ of the data were eliminated either because of track losses (momentary loss of eye position recording) in the target region or because the fixations on the targets were very short (under $100 \mathrm{msec}$ ). Consistent with prior research (Raney \& Rayner, 1995; Rayner et al., in press), in the reading condition subjects were more likely to skip the HF target word than to skip the LF target word; they fixated on the HF words $83 \%$ of the time and on the LF words $89 \%$ of the time $[t(15)=2.17, p<.05]$. However, in the search condition, there was no difference between the two types of target words, with subjects fixating on the HF and LF target words $80 \%$ of the time $(t<1)$.

Table 1 shows the fixation time on the target words in the reading and search conditions. First fixation duration is the duration of the first fixation on a target word independently of the number of fixations made on the word. Gaze duration is the sum of all fixations on a target word prior to a movement to another word. Separate 2 (task: reading vs. search) $\times 2$ (frequency: HF vs. LF) analyses of variance (ANOVAs) on the first fixation and gaze duration data were performed on the basis of both subject $\left(F_{1}\right)$ and item variability $\left(F_{2}\right)$.

The analysis of the first fixation duration data yielded a significant main effect of frequency, which was significant in the subjects analysis $\left[F_{1}(1,30)=6.54, M S_{\mathrm{e}}=\right.$ $352, p<.05]$ and marginally significant in the items analysis $\left[F_{2}(1,30)=3.26, M S_{\mathrm{e}}=765, p<.10\right]$. However, this effect was qualified by a significant interaction $\left[F_{1}(1,30)=\right.$ $7.68, M S_{\mathrm{e}}=352, p<.01$, and $F_{2}(1,30)=4.84, M S_{\mathrm{e}}=583$, $p<.01]$. Post hoc tests revealed that the frequency effect was significant in the reading condition $\left[F_{1}(1,15)=7.85\right.$, $M S_{\mathrm{e}}=660, p<.05$, and $F_{2}(1,30)=5.96, M S_{\mathrm{e}}=881, p<$ $.05]$ but not in the search condition $(F \mathbf{s}<1)$.

The analysis of the gaze duration data yielded significant main effects of both task $\left[F_{1}(1,30)=12.72, M S_{\mathrm{e}}=\right.$ $1,057, p<.01$, and $\left.F_{2}(1,30)=14.53, M S_{\mathrm{e}}=765, p<.01\right]$ and frequency $\left[F_{1}(1,30)=17.46, M S_{\mathrm{e}}=668, p<.001\right.$, and $\left.F_{2}(1,30)=12.75, M S_{\mathrm{e}}=934, p<.01\right]$. However, as with the first-fixation data, the interaction of the two

Table 1

First Fixation Duration (FFD) and Gaze Duration (Both in Milliseconds) for High-Frequency (HF) and Low-Frequency (LF) Target Words as a Function of Task

\begin{tabular}{llllll}
\hline & \multicolumn{2}{c}{ FFD } & & \multicolumn{2}{c}{ Gaze } \\
\cline { 2 - 3 } \cline { 5 - 6 } Condition & HF & LF & & HF & LF \\
\hline Reading & 248 & 273 & 272 & 325 \\
Search & 264 & 263 & & 269 & 270 \\
\hline
\end{tabular}

Note-Whereas in the reading condition most subjects occasionally refixated on target words (i.e., made additional fixations on a target word before moving to another word), in the search condition they typically did not make a second fixation on the target word before moving on. The slight increase in the means from first-fixation duration to gaze duration in the search condition are therefore due to the occasional refixations made on target words. variables was also significant $\left[F_{1}(1,30)=16.19, M S_{\mathrm{e}}=\right.$ $668, p<.001$, and $F_{2}(1,30)=14.23, M S_{\mathrm{e}}=765, p<$ $.001]$. Post hoc tests again revealed that the frequency effect was significant in the reading condition $\left[F_{1}(1,15)=\right.$ $19.1, M S_{\mathrm{e}}=1,176, p<.001$, and $F_{2}(1,30)=18.38, M S_{\mathrm{e}}=$ $1,240, p<.001]$ but not in the search condition $\left(F_{\mathrm{S}}<1\right)$.

Finally, examination of the global eye movement data as a function of task revealed that subjects' average fixation durations were shorter $(252 \mathrm{msec})$ in the search condition than in the reading condition $(276 \mathrm{msec})$, the average saccade length was longer in the search condition (11.2 letter spaces) than in the reading condition (8.1 letter spaces), and the frequency of regressions was lower in the search condition $(3 \%)$ than in the reading condition (18\%); all differences were significant $(p<.01)$.

\section{Discussion}

The results of this experiment are quite straightforward. When subjects were asked to read passages of text to comprehend the meaning, a frequency effect was reflected in the eye fixation times on the target words: Readers looked at LF words longer than at HF words. However when subjects engaged in a visual search task, no frequency effect was present in the eye fixation times. This result suggests that when comprehending the meaning of the text is not relevant, the trigger to move the eyes is different from what it is in reading for comprehension. In the present case, it would seem that a simple decision as to whether or not the currently fixated word was the search target would suffice.

An interesting question regarding the present results is whether or not lexical access of fixated words occurs in the search task. Given that it is very difficult to shut down lexical access once a word has been attended to (as shown by the Stroop effect, MacLeod, 1991), it would seem that lexical access occurred in the search task and that it was affected by lexical frequency. However, we would argue that in reading, the decision to move the eyes is influenced by lexical access because activation of meaning is critical to the reading process, whereas in visual search, the decision to move the eyes is determined by a more rapid surface comparison (even though lexical access is still likely to occur at a later point in time).

The results of our study are important not only because they confirm the hypothesis that the trigger to initiate an eye movement is different in visual search than in reading, but because they demonstrate that it is hazardous to generalize from one situation to the other. In this vein, Vitu et al. (1995) recently reported data from an experiment in which subjects (1) read text, (2) searched text to note all of the occurrences of the letter $c$, (3) pretended they were reading when all of the letters in the text were replaced by $z \mathrm{~s}$, or (4) searched through texts in which all of the letters were replaced by $z$ (except for the letter $c$ ) to note all occurrences of the letter $c$. On the basis of analyses of both global (distributions of saccade lengths and fixation durations) and local (skipping probability, initial landing sites in words, probability of refixating words, and positions of refixations in words) aspects of eye movement behavior in the four tasks, Vitu et al. concluded that the eyo movement characteristics were quite similar across the tasks. They further concluded that the similarity of the data in the different tasks was consistent with an oculomotor control model of eye movements during reading. However, in a recent extension of the Vitu et al. study, Rayner and Fischer (in press) demonstrated major differences in fixation times and the probability of refixating a word depending on whether the target was a high-frequency word, a low-frequency word, or a $z$-string.

Although the low-level oculomotor type of models of eye movement control in reading may be able to account for factors such as where the eyes land in a word, some aspects of skipping behavior, as well as some aspects of refixations, they do not do as good a job explaining fixation-time effects. In other words, oculomotor models may do a good job of explaining where to fixate next, but they do not do a very good job of explaining when to move. The moment-to-moment processing models, on the other hand, seem to do a good job of accounting for both aspects of eye movement control in reading (see also 
Rayner et al., in press). This may be due to the fact that the two decisions are somewhat independent in the moment-to-moment models, whereas in oculomotor models like O'Regan's, the decisions are not independent (see Rayner et al., in press).

\section{REFERENCES}

FRANCIS, W. N., \& KUČERA, H. (1982). Frequency analysis of English usage: Lexicon and grammar. Boston: Houghton Mifflin.

HENDERSON, J. M., \& FERREIRA, F. (1990). Effects of foveal processing difficulty on the perceptual span in reading: Implications for attention and eye movement control. Journal of Experimental Psychology: Learning, Memory, \& Cognition, 16, 417-429.

Hogaboam, T. W. (1983). Reading patterns in eye movement data. In $\mathrm{K}$. Rayner (Ed.), Eye movements in reading (pp. 309-332). New York: Academic Press.

INHOFF, A. W., \& RAYNER, K. (1986). Parafoveal word processing during eye fixations in reading: Effects of word frequency. Perception \& Psychophysics, 40, 431-439.

JUST, M. A., \& CARPENTER, P. A. (1980). A theory of reading: From eye fixations to comprehension. Psychological Review, 87, 329-354.

Kowler, E., \& ANTON, S. (1987). Reading twisted text: Implications for the role of saccades. Vision Research, 27, 45-60.

MACLeOD, C. M. (1991). Half a century of research on the Stroop effect: An integrative review. Psychological Bulletin, 109, 163-203.

MoRRISON, R. E. (1984). Manipulation of stimulus onset delay in reading: Evidence for parallel programming of saccades. Journal of $E x$ perimental Psychology: Human Perception \& Performance, 10, 667682.

O'Regan, J. K. (1990). Eye movements and reading. In E. Kowler (Ed.), Eye movements and their role in visual and cognitive processes (Vol. 4, pp. 395-453). Amsterdam: Elsevier, North-Holland.

O'REGAN, J. K. (1992). Optimal viewing position in words and the strategy-tactics theory of eye movements in reading. In $\mathrm{K}$. Rayner (Ed.), Eye movements and visual cognition: Scene perception \& reading (pp. 333-354). New York: Springer-Verlag.

POllatseK, A., \& Rayner, K. (1990). Eye movements and lexical ac- cess in reading. In D. A. Balota, G. B. Flores d'Arcais, \& K. Rayner (Eds.), Comprehension processes in reading (pp. 143-163). Hillsdale, NJ: Erlbaum.

Pollatsek, A., Rayner, K., \& Balota, D. A. (1986). Inferences about eye movement control from the perceptual span in reading. Perception \& Psychophysics, 40, 123-130.

RANEY, G. E., \& RAYNER, K. (1995). Word frequency effects and eye movements during two readings of a text. Canadian Journal of Experimental Psychology, 49, 151-172.

RAYNER, K. (1977). Visual attention in reading: Eye movements reflect cognitive processes. Memory \& Cognition, 5, 443-448.

RAYNER, K. (1995). Eye movements and cognitive processes in reading, visual search, and scene perception. In J. M. Findlay, R. W. Kentridge, \& R. Walker (Eds.), Eye movement research: Mechanisms, processes and applications (pp. 3-22). Amsterdam: Elsevier, NorthHolland.

RAYNER, K., \& DUFFY, S. A. (1986). Lexical complexity and fixation times in reading: Effects of word frequency, verb complexity, and lexical ambiguity. Memory \& Cognition, 14, 191-201.

RAYNER, K., \& FISCHER, M. H. (in press). Mindless reading revisited: Eye movements during reading and scanning are different. Perception \& Psychophysics.

Rayner, K., \& Pollatsek, A. (1992). Eye movements and scene perception. Canadian Journal of Psychology, 46, 342-376.

Rayner, K., Sereno, S. C., \& Raney, G. E. (in press). Eye movement control in reading: A comparison of two types of models. Journal of Experimental Psychology: Human Perception \& Performance.

SERENO, S. C. (1992). Early lexical effects when fixating a word in reading. In K. Rayner (Ed.), Eye movements and visual cognition: Scene perception and reading (pp. 304-316). New York: Springer-Verlag.

VITU, F., O'REgan, J. K., INHOFF, A. W., \& TOPOLSKI, R. (1995). Mindless reading: Eye-movement characteristics are similar in scanning strings and reading texts. Perception \& Psychophysics, 57, 352-364.

(Manuscript received July 12, 1995;

revision accepted for publication December 22, 1995.) 